\title{
Learning of VATS right lower lobe anterior-basal segmentectomy (S8) on a 3D printed simulator
}

\author{
Evangelos Koliakos, Matyas Pal, Michel Gonzalez, Thorsten Krueger, Jean Y. Perentes \\ Division of Thoracic Surgery, University Hospital of Lausanne, Lausanne, Switzerland \\ Contributions: (I) Conception and design: JY Perentes, E Koliakos; (II) Administrative support: JY Perentes, T Krueger, E Koliakos; (III) Provision of \\ study materials or patients: JY Perentes, E Koliakos, M Pal; (IV) Collection and assembly of data: JY Perentes, E Koliakos, M Pal; (V) Data analysis \\ and interpretation: JY Perentes, E Koliakos, M Pal; (VI) Manuscript writing: All authors; (VII) Final approval of manuscript: All authors. \\ Correspondence to: Dr. Jean Y. Perentes, MD-PhD, PD-MER. Division of Thoracic Surgery, University Hospital of Lausanne, Rue du Bugnon 46, \\ 1011 Lausanne, Switzerland. Email: Jean.perentes@chuv.ch.
}

Background: Thoracic Surgery has dramatically evolved over the past 15 years with a switch in practice
from exclusively open to a majority of minimal invasive approaches for the management of non-small cell
lung cancer (NSCLC) but also metastasis. For these indications, segmentectomies have become more
popular and have made an important comeback in the field. The current practice therefore represents a
challenge in the capacity of trained surgeons to teach these technically demanding surgeries to trainees in
a safe way. Here, we report our experience with 3D printed lung model simulators for the teaching of right
lower lobe anterior-basal segmentectomy (S8). Methods: We used 3D silicone printed lungs with an anatomy showing bronchis, veins and arteries up to the segmental level. With a weekly training protocol consisting of two residents supervised by a fellow and a staff surgeon, we worked the practical approach of minimal invasive right lower lobe anterior-basal segmentectomy (S8). Using the same instruments as in the operative theater and doing all dissection with the Harmonic ${ }^{\circledR}$ shears, we were able to perform, in a way comparable to a procedure in patients, the steps of segment 8 resection. We recorded the procedure, illustrated the anatomy and assessed the satisfaction of trainees with this approach.

Results: The video of a 3-port Video assisted thoracoscopic surgery (VATS) right lower lobe anterior-basal segmentectomy (S8) in a 3D printed silicone model is provided. We choose a trans-fissure approach where the interlobar artery was identified followed by the isolation and stapling of A8, B8 and V8. The parenchyma was then stapled along the intersegmental plan to extract the segment. The approach was satisfactory for residents who found the exercise useful to train thoracoscopic movements, to understand anatomy and the stepwise approach.

Conclusions: Simulation approaches are useful for the teaching of residents and could be a useful tool to integrate to the curriculum of trainees.

Keywords: Vats simulation; segmentectomy; lung box trainer; resident satisfaction

Received: 06 December 2021; Accepted: 27 January 2022; Published: 20 October 2022.

doi: 10.21037/jovs-21-67

View this article at: https://dx.doi.org/10.21037/jovs-21-67

\section{Introduction}

The surgical approach of non-small cell lung cancer (NSCLC) has dramatically changed over the past fifteen years. Thoracic surgery has switched from an almost exclusive open surgery to a majority of minimal invasive surgeries. This change has shown many advantages for lung cancer patients regarding quality of life improvements and postoperative pain decrease in prospective randomized trials (1-5). Video assisted thoracoscopic surgery (VATS) and robot assisted thoracic surgery (RATS) are now the most common modalities for lung cancer and metastasis surgery. 

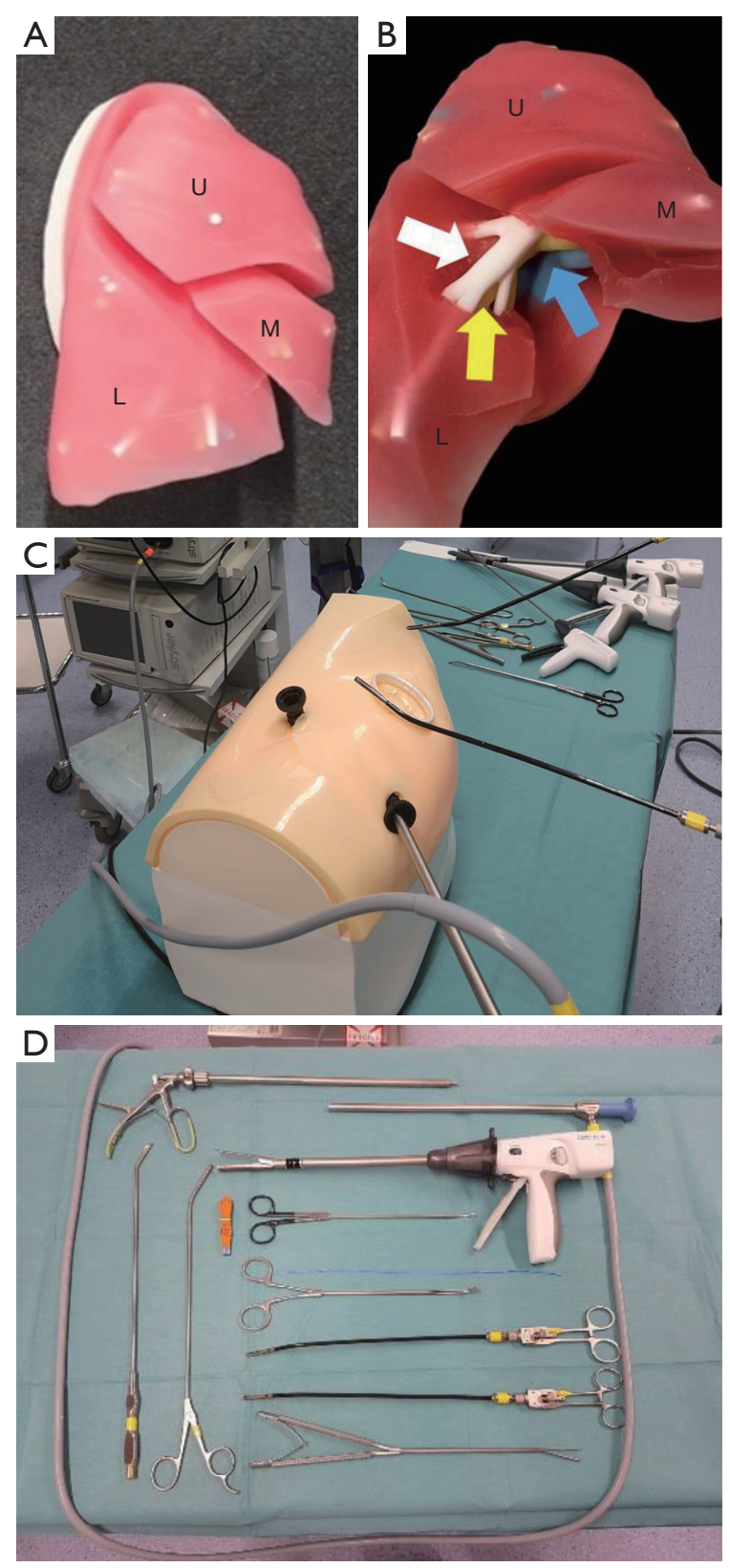

Figure 1 Description of the Stupnik simulator setup. (A) Stupnik $^{\circledR} 3 \mathrm{D}$ insert representing a right lung with the integrated representation of veins, arteries and bronchi. The upper, middle and lower lobes are represented by the letters $\mathrm{U}, \mathrm{M}$ and $\mathrm{L}$ respectively. (B) The silicone is removed to show the venous (blue arrow), arterial (white arrow) and bronchial systems (yellow arrow). The latter respect the standard anatomy of these systems in the insert. (C) Aspect of the simulator with a closed chest and the placement of the alexis mini and thoracoports. (D) Instrumentation for the making of the video.
These approaches are currently favored for operable NSCLC by the ESMO (European society of medical oncology), ESTS (European society of thoracic surgery) and ATS (American society of thoracic surgery) societies (1,6-8).

In parallel, segmentectomies have re-gained interest in the thoracic surgery field. Segmentectomy was long considered as inferior to lobectomy for the management of NSCLC in terms of recurrence and oncological prognosis (9). These were reserved for patients with low cardiopulmonary functions or for progressing small (less than $2 \mathrm{~cm}$ ) ground glass opacities. The evolution and quality of radiological imaging have since allowed to detect more early stage NSCLCs and contributed to an increase of interest in segmentectomy. Retrospective and prospective randomized trials comparing segmentectomy to lobectomy in small-sized peripheral NSCLC are encouraging and found comparable overall survival in both groups (10). It is thus likely that segmentectomies become more frequent in the field of thoracic surgery in the near future.

The training of young surgeons to minimal invasive surgery and segmentectomy is a challenge. Many thoracic surgery training programs have moved from being a specialization of general surgery to being a specific training per se. Residents with little surgical experience must be trained for complex procedures such as segmentectomy using minimal invasive approaches. It thus seems inevitable to have ex vivo training possibilities on simulators before performing these procedures on patients. Many different types of simulators have been developed all with advantages and disadvantages regarding realism and ease of use.

Here we illustrate a right lower anterior basal segmentectomy (S8) on a 3D printed silicone model used for teaching purposes. We show the realism of this simple simulator and report the surgical steps in a way similar to that of patients. We also report trainee satisfaction.

\section{Methods}

\section{Simulator}

We used a Stupnik ${ }^{\circledR}$ (Johnson and Johnson) 3D printed VATS Simulator model (Figure 1A). This consists of a silicone $3 \mathrm{D}$ printed right lung with a representation of the veins in blue, the arteries in white and the bronchi in yellow up to the segmental division (Figure 1B). This model is placed in an artificial chest consisting of plastic ribs 


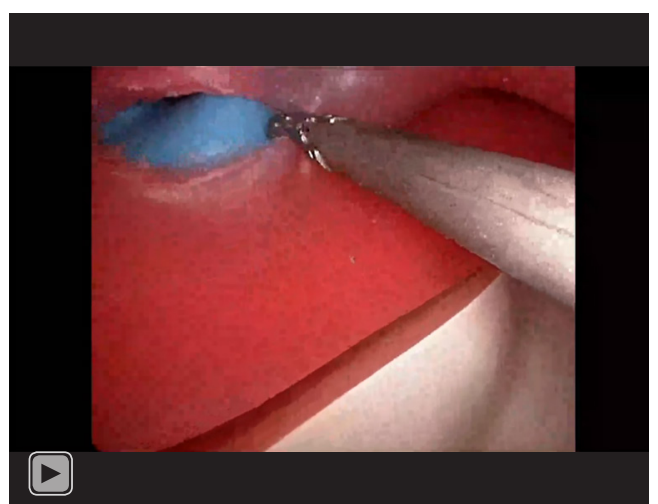

Video 1 The video shows the resection of segment 8 on the Stupnik ${ }^{\circledR}$ DD VATS simulator performed by a trainee and supervised by a staff surgeon. The steps of the resection are described with an anterior trans-fissure approach. VATS, Video assisted thoracoscopic surgery.

covered by artificial skin (made out of plastic and foam). This simulator allows for training of upper, middle and lower lobectomy as well as most segments. Its silicone can be dissected with forceps/scissors and also using heating energy devices such as Harmonic ${ }^{\circledR}$ (Johnson and Johnson). Three incisions were made on the chest wall: one utility incision at the $4^{\text {th }}$ intercostal space and two incisions at the $6^{\text {th }}$ intercostal space (Figure 1C).

\section{Tower and instruments}

A standard video thoracoscopy tower was used (Stryker) and we had the same instruments as in the operative theater (Scanlan VATS lobectomy instruments). All elements are represented in Figure 1D. The Stryker HD camera was docked on a $10-\mathrm{mm} 30^{\circ}$ thoracoscope. To dissect the silicone of the $3 \mathrm{D}$ insert, we used Harmonic ${ }^{\circledR}$ shears (Johnson and Johnson). The vessels (veins/arteries) and bronchi were stapled using Ethicon staplers $(45 \mathrm{~mm}$ blue staples for bronchi and lung parenchyma and $45 \mathrm{~mm}$ white staples for arteries and veins).

\section{Course organization}

The courses took place on weekly basis lasting 4 hours with two residents learning to perform segmentectomy procedures ( 6 residents in total) supervised by one fellow or staff surgeon. This simulation training was performed for 6 months. Each resident was operator or assistant for the procedure once. At the end of the course, the residents filled a satisfaction questionnaire.

\section{Video recording}

The right lower anterior basal segmentectomy (S8) was performed by a fellow and assisted by a staff surgeon. The procedure was recorded on the Stryker ${ }^{\circledR}$ video thoracoscopy tower and edited using Filmora9 (Wondershare corp ltd, Lhasa China).

The study was conducted in accordance with the Declaration of Helsinki (as revised in 2013). There was no ethical commission involved given that there were no patients.

\section{Results}

We performed all steps of a right lower anterior basal segmentectomy (S8) on the Stupnik simulator in a similar way to that in patients. We chose an anterior, three port approach.

The video of segment 8 resection was recorded (Video 1). Briefly, we started by dissecting the great fissure between the middle and inferior lobes to identify the inter-fissure artery as well as its branches destined to the middle lobe (A5), posterior segment of the upper lobe (A2), apical segment of the lower lobe (A6) and the basal segment of the lower lobe (basal segment artery). We then proceeded with the mediastinal pleural dissection and identification of the lower (V7-10) middle (V4-5) and upper lobe veins (V1-3). Finally, we identified the middle lobe bronchus in order to safely staple the anterior portion of the middle and lower lobe fissure. Then, by grasping the anterior portion of the lower lobe we were able to dissect the basal segment artery more distally and identify A7, A8 and A9 (A10 being more difficult to see through an anterior trans-fissure approach). We isolated A8 and divided it using a stapler. This allowed exposure of the bronchial system destined to the middle lobe and basal bronchus. The latter was dissected to identify B7, B8 and B9 and B8 was isolated and stapled. Finally, the veins were dissected and the branches identified (V7, V8 and V9). V8 was isolated and devided. The final steps of the segmentectomy consisted in the division of the intersegmental plane which was performed using the Harmonic and stapler.

Resident satisfaction was obtained using a questionnaire. All (6/6) were satisfied with the approach. All (6/6) found the model simple and thus still useful in the training of surgical movements, the understanding of the anatomy and 
the learning/establishment of a stepwise approach for S8 resection. All (6/6) felt more comfortable to understand and perform such a procedure on a patient and would recommend such a program as part of their surgical training.

\section{Discussion}

We report a novel training simulation training approach for residents to improve their performance for minimal invasive segmentectomy. This was possible with the use of a $3 \mathrm{D}$ printed lung that can be dissected in a similar way to a patient facilitating the recognition of anatomical landmarks. Overall, we believe the model allows $3 \mathrm{D}$ orientation in a chest, instrument placement and lung exposition, step by step structure identification and isolation, parenchyma sectioning and stapling. Resident satisfaction was great. We believe that this approach could be a useful adjunct in the training programs of residents. We chose to illustrate a S8 segmentectomy, however this 3D-printed model can also allow the training for all other types of segmental pulmonary resections.

\section{Current challenges in thoracic surgery training}

The training in thoracic surgery in Switzerland was, until 2015, a sub-specialty of general surgery. Thoracic surgery trainees thus all had a board of general surgery with a good experience in basic surgical skills but also laparoscopic/ thoracoscopic procedures. Since 2015, thoracic surgery has become a training per se with a requirement of only 2 years in general surgery. During the same period, most thoracic surgery cases went from exclusively open (with easy control of the vascular and bronchial central structures) to minimal invasive approaches. This has created a challenge for the training of residents by staff surgeons. To overcome this, ex vivo training programs have emerged with the aim to better prepare trainees to minimal invasive surgeries. In particular, surgical dexterity, 3D orientation, anatomy comprehension and instrument device handling can be learned on these simulators. Simulation training was proven to be a valuable asset in modern era surgical residency and fellowship programs. Simulation can shorten the initial steep part of the learning curve so that unexperienced surgeons reach a higher proficiency level before arriving in the operating room. These approaches help skill acquisition without exposing patients to complications related to operators' inexperience (11). In this study, we show that the combination of a simulator with a recurrent structured training period allowed for good resident satisfaction and realistic teaching approaches. We believe that the dyad training with a more experienced surgeon offers the best results and satisfaction as opposed to self-training. This is supported by the literature where educator guided simulation programs helped better recognize the learners' strengths and weaknesses, addressing personal learning objectives and providing real-time feedback (12). This enhanced the participants' motivation and performance $(12,13)$. Also, dyad training seems to make the course more cost/time efficient $(13,14)$. Altogether, evidence from the literature and our experience suggest that such training programs could be interesting adjuncts to the training of residents. In our institution, we have integrated these course on a weekly schedule and have made them mandatory. It will be essential in the near future to assess objectively how such courses impact the performance of trainees on real cases. A study is currently being planned with this objective.

\section{Simulators in thoracic surgery}

Currently, there is a wide range of simulation training methods available for VATS that belong to two main categories: "dry" or "wet" modules. Wet lab modules are considered as the ideal training platform due to their realistic feedback and real tissues/anatomy they provide. For this reason, Swine wet labs are very commonly used in the field of thoracic surgery (15). However, ethical and hygiene concerns make their use difficult and limited (16). Dry modules include box trainers, surgical simulators with evaluation software, virtual reality (VR) and augmented reality (AR) tools, synthetic mannequins and more recently, 3-dimensional (3D) printed anatomically accurate replicas of organs. The main disadvantages of VR and AR tools include costs and the lack of flexibility of the models which are designed for one specific procedure (17). On the other hand, 3D printed simulation models seem to be a good compromise offering a descent feedback, accurate anatomical representation and ease of use. We chose here a 3D printed silicone model. The costs of such an approach could be covered by industry sponsoring (see conflicts of interest) and the inserts could be used for more than one procedure. We found that the compatibility of this model with the surgical instruments and the prominent haptic feedback, made the overall training experience relatively close to reality. It allowed a good surgical reflex training regarding tissue handling, economy of movements 
and overall technical dexterity. The essential anatomic structures required for pulmonary anatomy teaching were present. Some elements still require improvement: the rigidity of the silicone parenchyma remains problematic. We have noticed that the training of basal or posterior segmentectomies was more challenging for exposure in the model. This type of issue could be overcome by the development of an insert with a softer silicone. Some movements are more difficult to perform than in real surgery (i.e., fissure completion, exposure) and falsely give the information of an increased strength maneuver which could lead to lesions on patients.

\section{Integration in the standard cursus and library for preparation of cases}

Our results and evidence found in the literature suggest that simulator based educational programs should be an adjunct in the curriculum of minimal-invasive surgery training. Although most available data on this subject occur from visceral surgery and gynecology (18), we believe that they hold true in thoracic surgery. Over a very short training period, our impression was that resident $3 \mathrm{D}$ orientation, hand coordination and trainee satisfaction improved. Ideally, multiple simulators, which all specifically help improve some aspects of the surgery, should be proposed to residents. This should facilitate the capacity of residents to perform surgeries in patients and improve their exposure to these frequent and still challenging situations.

\section{Conclusions}

Simulation training has gained an important role in modern surgical education over the past years. In the field of thoracic surgery, a discipline that has exponentially evolved during the last decade with a radical shift over minimalinvasive techniques, simulation training can be beneficial in shortening the learning curve and in helping young surgeons master new techniques in a controlled and safe environment. We believe that simulation training should complement current thoracic surgery residency programs. For this reason, we have established a training course with increasingly complex objectives that are performed by trainees of our division during weekly simulation sessions.

\section{Acknowledgments}

Funding: None.

\section{Footnote}

Provenance and Peer Review: This article was commissioned by the editorial office, Fournal of Visualized Surgery for the series "VATS Segmentectomy". The article has undergone external peer review.

Data Sharing Statement: Available at https://jovs.amegroups. com/article/view/10.21037/jovs-21-67/dss

Peer Review File: Available at https://jovs.amegroups.com/ article/view/10.21037/jovs-21-67/prf

Conflicts of Interest: All authors have completed the ICMJE uniform disclosure form (available at https://jovs. amegroups.com/article/view/10.21037/jovs-21-67/coif). The series "VATS Segmentectomy" was commissioned by the editorial office without any funding or sponsorship. The authors report that Ethicon (Johnson and Johnson) have financed the training laboratory they have used in this study. MG served as the unpaid Guest Editor of the series. The authors have no other conflicts of interest to declare.

Ethical Statement: The authors are accountable for all aspects of the work in ensuring that questions related to the accuracy or integrity of any part of the work are appropriately investigated and resolved. The study was conducted in accordance with the Declaration of Helsinki (as revised in 2013). There was no ethical commission involved given that there were no patients.

Open Access Statement: This is an Open Access article distributed in accordance with the Creative Commons Attribution-NonCommercial-NoDerivs 4.0 International License (CC BY-NC-ND 4.0), which permits the noncommercial replication and distribution of the article with the strict proviso that no changes or edits are made and the original work is properly cited (including links to both the formal publication through the relevant DOI and the license). See: https://creativecommons.org/licenses/by-nc-nd/4.0/.

\section{References}

1. Bendixen M, Jørgensen OD, Kronborg C, et al. Postoperative pain and quality of life after lobectomy via video-assisted thoracoscopic surgery or anterolateral thoracotomy for early stage lung cancer: a randomised controlled trial. Lancet Oncol 2016;17:836-44. 
2. Mohiuddin K, Swanson SJ. Maximizing the benefit of minimally invasive surgery. J Surg Oncol 2013;108:315-9.

3. Falcoz PE, Puyraveau M, Thomas PA, et al. Videoassisted thoracoscopic surgery versus open lobectomy for primary non-small-cell lung cancer: a propensitymatched analysis of outcome from the European Society of Thoracic Surgeon database. Eur J Cardiothorac Surg 2016;49:602-9.

4. Petersen RP, Pham D, Burfeind WR, et al. Thoracoscopic lobectomy facilitates the delivery of chemotherapy after resection for lung cancer. Ann Thorac Surg 2007;83:12459; discussion 1250.

5. Rodgers-Fischl PM, Martin JT, Saha SP. Video-Assisted Thoracoscopic versus Open Lobectomy: Costs and Outcomes. South Med J 2017;110:229-33.

6. Seder CW, Salati M, Kozower BD, et al. Variation in Pulmonary Resection Practices Between The Society of Thoracic Surgeons and the European Society of Thoracic Surgeons General Thoracic Surgery Databases. Ann Thorac Surg 2016;101:2077-84.

7. Howington JA, Blum MG, Chang AC, et al. Treatment of stage I and II non-small cell lung cancer: Diagnosis and management of lung cancer, 3rd ed: American College of Chest Physicians evidence-based clinical practice guidelines. Chest 2013;143:e278S-313S.

8. Batchelor TJP, Rasburn NJ, Abdelnour-Berchtold E, et al. Guidelines for enhanced recovery after lung surgery: recommendations of the Enhanced Recovery After Surgery (ERAS(R)) Society and the European Society of Thoracic Surgeons (ESTS). Eur J Cardiothorac Surg 2019;55:91-115.

9. Ginsberg RJ, Rubinstein LV. Randomized trial of lobectomy versus limited resection for T1 N0 non-small

doi: $10.21037 /$ jovs-21-67

Cite this article as: Koliakos E, Pal M, Gonzalez M, Krueger T, Perentes JY. Learning of VATS right lower lobe anteriorbasal segmentectomy (S8) on a 3D printed simulator. J Vis Surg 2022;8:34. cell lung cancer. Lung Cancer Study Group. Ann Thorac Surg 1995;60:615-22; discussion 622-3.

10. Suzuki K, Saji H, Aokage K, et al. Comparison of pulmonary segmentectomy and lobectomy: Safety results of a randomized trial. J Thorac Cardiovasc Surg 2019;158:895-907.

11. Stefanidis D, Hope WW, Korndorffer JR Jr, et al. Initial laparoscopic basic skills training shortens the learning curve of laparoscopic suturing and is cost-effective. J Am Coll Surg 2010;210:436-40.

12. Brydges R, Dubrowski A, Regehr G. A new concept of unsupervised learning: directed self-guided learning in the health professions. Acad Med 2010;85:S49-55.

13. Bjurström JM, Konge L, Lehnert P, et al. Simulation-based training for thoracoscopy. Simul Healthc 2013;8:317-23.

14. Wulf G, Shea C, Lewthwaite R. Motor skill learning and performance: a review of influential factors. Med Educ 2010;44:75-84.

15. Noda M, Mizuma M, Maeda S, et al. Presented at the 64th Annual Scientific Meeting of the Japanese Association for thoracic surgery: wet-lab training for thoracic surgery at the laboratory animal facilities. Gen Thorac Cardiovasc Surg 2012;60:756-9.

16. Bedetti B, Schnorr P, Schmidt J, et al. The role of wet lab in thoracic surgery. J Vis Surg 2017;3:61.

17. Qin Z, Tai Y, Xia C, et al. Towards Virtual VATS, Face, and Construct Evaluation for Peg Transfer Training of Box, VR, AR, and MR Trainer. J Healthc Eng 2019;2019:6813719.

18. Mannella P, Malacarne E, Giannini A, et al. Simulation as tool for evaluating and improving technical skills in laparoscopic gynecological surgery. BMC Surg 2019;19:146. 